ALPHA N² 27 Diciembre 2008 (9-28)

ISSN 0716-4254

http://alpha.ulagos.cl

\title{
REVISIÓN DEL MESTIZAJE EN LA OBRA DE HENRÍQUEZ UREÑA. ARMONÍAS SELECTIVAS, OMISIONES Y HUMANISMO EN UNA TEORÍA CULTURAL
}

Revision of the miscegenation in the works of Henríquez Ureña. Selective harmonies, omissions and humanism in a cultural theory

Claudio Maíz*

Resumen

A partir de una perspectiva situada a considerable distancia de una admisión sin problematizaciones del programa cultural del humanista dominicano Pedro Henríquez Ureña, se acomete una lectura crítica de la teoría del mestizaje como fuente de armonía e integración sociocultural de Hispanoamérica que enhebra gran parte de sus textos. Se pretende averiguar si la idea del mestizaje, en el que se involucra el elemento autóctono y español, se lleva adelante merced a algunas selecciones estratégicas, por ejemplo, el recorte de una imagen de Hispanoamérica a expensas del área caribeña y, consecuentemente, de otras reservas étnicas existentes.

Por otro lado, se plantea si el recurso de la fusión o mestizaje no resulta, a la postre, un modo solapado de eludir la conflictividad e inestabilidad cultural del Continente. Finalmente, se busca ponderar las causas por la cuales se adhiere firmemente al humanismo como una doctrina conveniente para el curso de la argumentación armonizadora de los elementos diferenciados, sin descuidar algunas notas positivistas que podrían perdurar en las alusiones a la raza.

Palabras clave: mestizaje cultural, humanismo, ensayo.

\section{Abstract}

From a perspective located at a considerable distance from an admission without any problematics of the cultural program of the Dominican humanist Pedro Henríquez Ureña, we propose a critical reading of the theory of miscegenation as a source of harmony and sociocultural integration of Hispanic-America that threads a great amount of the author's texts. Our working hypothesis tries to question the idea of Miscegenation, in which the autochthonous and Spanish elements interfere, and functions at the mercy of some strategic selections; for example, the clipping of an image of Spanish America at the expense of the Caribbean area and, consequently, of other existing ethnic reserves. On the other hand, we propose that the resource of the merger or miscegenation does not prove, at last, a sly way of eluding the conflict and cultural instability of the continent. Finally, we wish to consider the reasons for which he sticks fast and firmly to humanism as a suitable doctrine to set the course for an 


\section{Claudio Maíz}

argumentation of harmony for these very different elements, without neglecting any positivists notes which might last in the allusions to race.

Key words: cultural mestization, humanism, essay.

¿Las premisas que arrimó el posmodernismo a la crítica cultural hispanoamericana mejoran la exploración de la obra de Pedro Henríquez Ureña? Es sabido que en la actual tendencia al fragmento no parece haber demasiada propensión a valorar ciertas obras que son vistas con sentido museístico, enclavadas en el pasado y más reservadas a la exhibición que al ánimo inquisidor, a la espera de revelar en ellas nuevas orientaciones.

Cuestionados como han sido los principios totalizadores, las concepciones panorámicas o los relatos maestros, elaboraciones que están en la base de la obra crítica del dominicano, poco o nada restaría por preguntarle. Muy corto, empero, sería nuestro camino si tan sólo nos limitáramos a constatar que la obra en cuestión está signada por proyectos globales emanados de una inteligencia romántica e historicista. Carecería de sentido, desde luego, la pregunta inicial. Cada texto graba el marco contextual en el que se produce y ello en Henríquez Ureña resulta extremadamente evidente.

En efecto, Henríquez Ureña formó parte de una promoción de intelectuales que elaboró un discurso más amplio que el académico, podría decirse incluso contrario a él, ya que el interés por los grandes problemas americanos lo condujo hacia visiones holísticas e integradoras de otros saberes (políticos, sociales, estéticos). Si resulta computable como un acierto para el momento de su actuación —al decir de Beatriz Sarlo— el "peligro que acecha a este tipo de discurso es el de las generalidades" (Sarlo, 2000:880) en las que, a veces, incurre el dominicano con la esperanza de hallar el tiempo necesario para convertir algunas de sus "iluminaciones" en discursos más y mejor desarrollados.

Sin embargo, hay dos circunstancias que salen en favor de Henríquez Ureña: una textual y otra existencial. En cuanto a la primera, Henríquez Ureña es, ante todo, un ensayista en el más cabal sentido del término, es decir, reúne en un mismo discurso el talento de una observación y la preocupación estética por la forma como se la expresa. La distancia con la academia debe medirse, también, desde el género discursivo en el que da a conocer su pensamiento. No siente pasión por el tratado (la magna obra) ni anhela la escritura puramente erudita; por ello lo mejor de su prosa está en la brevedad ensayística. Debemos admitir entonces el siguiente oxímoron: la aspiración a la totalidad, el hálito panorámico están en relación directa con la brevedad del 
género elegido. ${ }^{1}$ En segundo término y vinculado con esto, está la condición existencial del exilio al que debió someterse — como la marca del intelectual moderno hispanoamericano- siguiendo una antigua tradición continental. La vida del exilio le imprime a los tiempos de producción otras secuencias muy diferentes a las del intelectual que se asienta en una nación sin dificultades.

Otras temporalidades, renovación permanente de los temas, abandono de bibliotecas, serían algunas de las dificultades del exiliado que impiden una labor más serena y la posibilidad de desplegar mejor la obra. ${ }^{2}$ Circunstancia, sin embargo, que le facilita observaciones más amplias que las meramente nacionales. En suma, el origen de la tendencia totalizante del escritor dominicano no es por cierto único. Aunque sea ésta una tonsura epocal perceptible en su obra, es preciso sumar a la explicación el género discursivo elegido y la tradición del desplazamiento permanente en el que se inscribe. En el cruce de las preguntas que procuró responder y las condiciones epocales en las que lo hizo, se podría encontrar el punto más equilibrado, sin caer en el rechazo de sus postulados ni sucumbir a las estrategias persuasivas que operan en su obra.

\section{EL CARIBE MULTIFORME}

Sin pretender que la pregunta inicial nos obligue a una evaluación crítica del posmodernismo ${ }^{3}$ a través de una confrontación de sus principios, la formulamos con el propósito de abordar los contenidos de la obra de Henríquez Ureña con otro contexto epistemológico. Nos parece un ejercicio pertinente hacerlo, más específicamente, desde la perspectiva, muy singular por cierto, de Antonio Benítez Rojo (1989). Ante todo, porque en el escritor cubano merece subrayarse que la lectura posmoderna del Caribe que propone no deslegitima ni invalida otras sobre el mismo espacio geocultural, lo cual vale también para Henríquez Ureña, aunque su forma de leer el Caribe se asiente más que nada en la omisión. Tampoco que ninguna de ellas pueda ser considerada falsa sino que son tan necesarias y "tan potencialmente productivas como lo es la primera lectura de un texto, en la cual,

\footnotetext{
${ }^{1}$ Cfr. Claudio Maíz. El ensayo entre género y discurso. Mendoza: Editorial de la Facultad de Filosofía y Letras, 2004.

${ }^{2}$ En su trabajo sobre los beginnings, es decir, el estudio del imaginario de los principios de Henríquez Ureña, Díaz Quiñones se interesa por tres vertientes superpuestas y orientadoras en su investigación: la elaboración de una tradición nacional dominicana, el exilio como condición moderna y la identificación entre cultura y orden (2006:174-5).

${ }^{3}$ Tarea, por lo demás, llevada acabo de manera pormenorizada por un importante número de críticos culturales.
} 


\section{Claudio Maíz}

inevitablemente, como decía Barthes, el lector se lee a sí mismo” (Benítez Rojo, 1989:II).

La perspectiva de Benítez Rojo no deslegitima ninguna otra emprendida con anterioridad a la suya, sólo pone de manifiesto un criterio no jerárquico, si se quiere, horizontal. Sin embargo, bien mirado el asunto, mediante la distinción entre una primera lectura autorreflexiva ("el lector se lee a sí mismo") y la relectura en la que se empieza a "revelar la propia textualidad" deja establecida una jerarquía paralela a la supuesta horizontalidad en la que se ordenaban las lecturas anteriores. Este distingo nos parece relevante puesto que facilita una manera de leer también algunos textos de Henríquez Ureña, procurando despojar aquellas miradas autorreflexivas anteriores; es decir, aquellas lecturas que no hacían sino decodificar los mismos principios que el lector esgrimía y que el texto se limitaba a refrendar. Pienso en las corrientes fuertemente europeístas, como la de la Revista Sur y su directora Victoria Ocampo con la que Henríquez Ureña tuvo tan buena afinidad. También, pienso en la rápida aceptación de la que fue objeto su obra en la academia norteamericana. $\mathrm{O}$ en las lecturas que el hispanismo ha efectuado subrayando la intensa adhesión del dominicano al legado español. En ésas, como en otras lecturas de semejante índole, pueden hallarse los ejemplos de una cierta autorreflexividad, sin que todavía el texto "hable” más allá de lo que el lector lo deja. De ahí que el método de lectura no especular que propone Benítez Rojo parezca idóneo para desbrozar las diversas lecturas que el cuerpo textual del dominicano ha acumulado. De este modo, algunos supuestos posmodernos empezarían a mostrar la solvencia para releer algunos tópicos en la obra del dominicano.

La tesis central del ensayo de Benítez Rojo se basa en que la cultura es un discurso, un lenguaje y, como tal, fluye de manera permanente; siempre en estado de transformación, a la búsqueda de significar lo que no alcanza a significar. La inestabilidad de la cultura como discurso está bien lejos del concepto de Henríquez Ureña, a pesar de que — para el dominicano "en su teoría y práctica” - la cultura hispanoamericana contiene además de la historia literaria, las instituciones, la historia de las ideas, la historia social, la pintura, la música; todo ello en el marco "nacional”. La concepción de la cultura de Henríquez Ureña se describe como "fuerte", es verdad, entendida como "sujeto de la historia y como objeto de estudio". De ningún modo como vacilante o fluctuante, menos aún si el acople de la cultura hispanoamericana se hace con la tradición occidental, gracias a la cual el dominicano construye uno de los "grandes relatos" legitimantes de "una identidad integradora" (2006:172).

¿Cómo se reconcilian, en suma, la inestabilidad del flujo cultural como discurso (posmoderno) con la estabilidad del mestizaje en tanto teoría 
integradora? ¿Es que existe tal posibilidad? Para decirlo de una vez, la argumentación de Benítez Rojo se alza contra el mestizaje entendido a la manera de una tradición culturológica que ha hecho de la mezcla la más plausible de las explicaciones sobre la cultura latinoamericana. Partiendo de la idea de que "un artefacto sincrético no es una síntesis, sino un significante hecho de diferencias", su relectura pondría en evidencia que el mestizaje no es una síntesis sino, más bien, su contrario. No lo puede ser por el hecho de que nada sincrético constituye un punto estable. Y agrega: "El elogio del mestizaje, la solución del mestizaje, no es originaria de África ni de Indoamérica ni de ningún Pueblo de Mar”. A su manera de ver, se trata de un argumento positivista y logocéntrico, un argumento que ve en "el blanqueamiento biológico, económico y cultural de la sociedad caribeña una serie de pasos sucesivos hacia el progreso" y, por lo tanto, "se refiere a la conquista, la esclavitud, la neocolonización y la dependencia” (Benítez Rojo, 1989:XXVI).

Es evidente que, además de alzarse contra el mestizaje, el texto de Benítez Rojo lo hace contra las ideas esencializadoras de la identidad. La misma inestabilidad y turbulencia del Caribe hace impensable poner en juego la obsesión ontológica, en la que se demanda un centro irradiante de legitimidad. La repetición de los tropismos, esa "cierta manera" de actuar que le atribuye a la cultura caribeña fluctúa y se desplaza como buena hija de una cultura de los Pueblos de Mar. La apretada síntesis de la visión caótica e inestable con la que Benítez Rojo retrata a la cultura del Caribe constituye, probablemente, el epítome de lo que con tanto ardor supo rechazar Pedro Henríquez Ureña.

\section{LA MIRADA A HISPANOAMÉRICA: OMITIR Y OLVIDAR}

No nos ocuparemos aquí estrictamente del Caribe, como podría sugerirlo la repetida alusión que hemos hecho de él, a lo que se suma la glosa a un ensayo referido a ese espacio. Quizás, lo podría ser de manera indirecta, ya sea por la nacionalidad dominicana, por tanto caribeña, de Henríquez Ureña o por algunos de los trabajos que le dedicó a la Isla donde nació. Nada de eso. Nuestro enfoque asume el Caribe como una figura ausente, y como un recorte en el atlas conceptual de Henríquez Ureña. He ahí nuestro interés. No es lo que escribió (poco en verdad) sobre el Caribe lo que nos llama la atención, entonces, sino la operación mediante la cual lo dejó fuera al confeccionar los bordes de la figura americana inscrita en su producción. Omitir la inestabilidad caribeña — dicho esto en un sentido amplio que va más allá de lo político - es, también, una manera de aludir a la identidad y al mestizaje que sí fueron sus preocupaciones centrales. En un cuadro 


\section{Claudio Maíz}

conformado de ausencias, recortes y omisiones es donde intentamos formularnos las interrogantes antes indicadas. La preocupación por el orden y el idioma son dos enclaves firmes que a Henríquez Ureña le merman atracción por las áreas que están sumidas tanto en el caos político como, en cierto modo, el caos lingüístico. Con el fin de crear una imagen homogénea, unitaria, continua de Hispanoamérica, Henríquez Ureña compatibiliza en un mismo haz de significaciones la tradición "nacional", la "hispanoamericana" y la "cosmopolita". Toma al conjunto de estas líneas ni más ni menos que como sensibilidades confluyentes, con diferencias - lo reconoce- pero intrascendentes a la hora de declarar la pertenencia a la gran estirpe románica. ("Pertenecemos a la Romania" repite en varias ocasiones). En "El descontento y la promesa", lo declara abiertamente: formamos parte de "la familia románica que constituye todavía una comunidad, una unidad de cultura, descendiente de la que Roma organizó bajo su potestad; pertenecemos —según la repetida frase de Sarmiento- al Imperio Romano” (2000:283). En semejante legado los matices si no se disuelven al menos no alcanzan ni siquiera a perturbar el gran edificio - ese hogar de armonía y saber- de la herencia occidental que Hispanoamérica integra. Por lo tanto, no hay incompatibilidad porque no hay diferencias relevantes ni conflictos entre aquellos niveles culturales. Este primer gran nudo existe gracias a la epifanía de la continuidad, que sutura los andariveles de lo nacional-hispanoamericano, por un lado, y de lo europeo, por el otro, sin trauma alguno. Otro gran supuesto parte de la negación del mundo afrocaribeño. Díaz Quiñones hace notar que esa negación llevó a que Henríquez Ureña postulara "un abismo infranqueable entre lo dominicano y lo haitiano que asumió en un momento la forma de investigaciones "dialectológicas” de sobretonos racistas" (2006:174). Pero este desliz — si así se lo puede llamar — no se limita a la rivalidad haitiano-dominicana, en la que claramente toma partido por su isla natal, sino que se constata en ciertas caracterizaciones sociales presentes en la intimidad de sus Memorias (1989), como cuando escribe: "Con Dávalos vive una hermana suya, idiota; al verla, se la supone una sirviente, pues el traje que usa es burdo y del tipo de mestiza del pueblo"; o en el mismo pasaje, cuando al referirse a los orígenes sociales de las mismas personas, aflora una distinción entre "gente respetable" y refinada y los "otros"

Después de todo, mucho hay que conceder a quien con tan pobre origen ha logrado colocarse en posición estimable. Pues, a pesar de las desventajas sociales e intelectuales que todavía previenen a muchos contra Marcelino, éste ha trabajado como pocos y, si no le aceptan los jóvenes refinados, ha logrado grande estimación entre las gentes 
respetables, consagradas, de no muy buen gusto, pero de prestigio popular (1989:168).

La obsesión por el origen vuelve, cuando en sus memorias Henríquez Ureña se ocupa de su amigo Jesús T. Acevedo: "hay no sé qué elemento de origen que lo ata a las cosas bajas. Entiendo que sus padres son muy honorables y modestos, pero sé que algunos de sus hermanos se han descarriado" (1989:188).

Una lectura desestabilizadora — como la que practica Benítez Rojonos pone en condiciones de revisitar la obra de Henríquez Ureña desde una perspectiva menos firme ni autocomplaciente, obligándonos a concentrarnos no tanto en nuestras propias nociones, sino en lo que el texto tendría aún por decir. No estamos proponiendo una operación fantasmagórica, mediante la que el texto se independiza y dicta su propia bitácora de lectura. Se trata de juegos de lecturas que involucran desde el texto del dominicano hasta los textos que lo usufructuaron en sus propias lecturas. Con todo, queremos evitar caer en operaciones especulares o paradójicas, aunque en algunas de ellas sea inevitable reconocerlas. Tal es el hecho de que el texto de Henríquez Ureña se problematiza en relación con el de Benítez Rojo desde el momento en que, para el dominicano, el Caribe no constituye ni de lejos el eje central de toda su actividad reflexiva y escritural. Antes bien, es más seguro encontrar una serie de especulaciones que lo tornan en un hostigador de ese espacio. De esta afirmación, no obstante, deben descontarse sus estudios sobre la cultura y la literatura dominicana, como La cultura y las letras coloniales en Santo Domingo (1936) o El español en Santo Domingo (1940). En apretada síntesis, se puede decir que no hay en Henríquez Ureña una inclinación por los temas que no tengan que ver con el legado hispánico, por una central razón lingüística: ya sea con afán comparativo o contrastivo, el viejo tronco peninsular siempre se impone. De tal manera, entonces, queda fuera de sus requisitorias la raíz africana o la inmigración india que, entre otras características, signan el Caribe; como también las corrientes inmigratorias de comienzos del siglo XX especialmente en el área rioplatense.

\section{HUMANISMO, ORDEN Y TRADICIÓN}

Ahora bien, la mirada de Benítez Rojo hace más notoria la ausencia del Caribe en la obra de Henríquez Ureña. Asimismo, sería posible marcar otra ausencia tan evidente como la anterior: la del mundo lusitano del Brasil. Ambas omisiones no hacen sino resaltar el nítido recorte que traza Henríquez Ureña asentado en la lengua española. Hay algo común tanto en el Caribe como en el Brasil: la raíz africana. La solución excluyente que implementa 


\section{Claudio Maíz}

para el diseño de su idea hispanoamericana afirmada en la lengua española constituye uno de los más sólidos basamentos de sus reflexiones. Otro, no menos inquietante, es la falta de conflicto, categoría que está fuera de la trama del ensayista. El conflicto se sustituye con el optimismo. Durante su estancia en Nueva York escribe: "nunca tuve allí un momento de pesimismo; tanto en verso como en prosa, me convertí al optimismo más franco, creí en el progreso, en el porvenir de la humanidad, otras fantasías muy en boga en estos tiempos" (1989:124). O en otro lugar de sus Memorias, sostiene "Yo, en cambio, estaba en plena época positivista y optimista" (128). Sarlo, trazando algunos paralelismos con los intelectuales que actúan en el mismo tiempo que el dominicano, advierte que Henríquez Ureña no se hace cargo del pensamiento de Mariátegui ni de González Prada, a pesar de tener inquietudes en común. La respuesta que ensaya en esta indiferencia está ligada a "la inflexión optimista del pensamiento de Henríquez Ureña”.

La inflexión - continúa Sarlo- tiene como consecuencia que el conflicto (social, cultural, racial) no esté ubicado como categoría central: el conflicto es un dato en verdad subordinado, que el impulso de la utopía resolverá, como ha resuelto las crisis nacionales del siglo XIX. Esta dimensión optimista explica la imposibilidad profunda de hacerse cargo del pensamiento de Mariátegui. No buscaría la causa en el espiritualismo de Henríquez Ureña, sino en su optimismo (2000:885).

Tal optimismo le resta horizonte a Henríquez Ureña para la comprensión de la historia en un sentido más agónico, dialéctico o imperfecto, al menos. Habría que averiguar más profundamente si esta negación del conflicto no sería otra manera de manifestar su horror vacui no sólo a carecer de una tradición sino, también, al otro rechazo: el de las fuerzas anarquizantes que constata a lo largo del siglo XIX hispanoamericano y en la caótica vida institucional y política del Caribe. Díaz Quiñones estableció como una de las líneas de sus beginnings "la estrecha identificación entre cultura y orden". Para el dominicano, la modernidad consistía en un enfrentamiento entre orden y anarquía (2006:176). De aquí, probablemente, le viene la distinción entre países “serios” y "tropicales”. Esa tendencia (propagada desde la Argentina) divide a los países en dos grupos únicos: "la América mala y la América buena, la tropical y la otra, los petits pays chauds y las naciones bien organizadas (1978:50). Con esta distinción quedaba sellada, incluso, la suerte misma de la literatura

La divergencia de las dos América, la buena y la mala, en la vida literaria, sí comienza a señalarse, y todo observador atento la habrá advertido en los años últimos; pero en nada depende de la división en zona templada y zona tórrida. La fuente está en la diversidad de cultura. 
Durante el siglo XIX, la rápida nivelación, la semejanza de situaciones que la independencia trajo a nuestra América, permitió la aparición de fuertes personalidades en cualquier país: la Argentina producía un Sarmiento, el Ecuador a Montalvo; si México a Gutiérrez Nájera, Nicaragua a Rubén Darío. Pero las situaciones cambian: las naciones serias van dando forma y estabilidad a su cultura, en ella las letras se vuelven actividad normal; mientras tanto, en cultura, tanto elemental como superior, son víctimas de los vaivenes políticos y del desorden económico, la literatura ha comenzado a flaquear (1978:52).

Con todo, Henríquez Ureña intuye que no se trata de un problema climático del determinismo naturalista sino de densidad cultural, es decir, la capacidad de los países para diversificar su cultura a través del recurso de abrirla a otras voces. Pero, mientras el desarrollo general de los países durante el siglo XIX era más o menos parejo y, por lo tanto, las producciones culturales de las diversas naciones no acusaban grandes diferencias, durante el siglo XX las cosas cambiarán sustancialmente a tal punto que la superioridad cultural y literaria depende, en gran medida, del grado de desarrollo de una nación. Ahora se sopesa de otra manera el producto cultural o literario. En consecuencia, la carrera por la primacía literaria será ganada por la "América buena" en detrimento de las naciones que componen la "América mala" (1978:52). De esta manera, el dominicano alienta una teoría de la producción literaria y cultural ligada al desarrollo económico de una nación. José Carlos Mariátegui se entusiasma con este carácter "progresista" de la visión de Henríquez y va más allá en la interpretación del pasaje que estamos comentando. Sin hesitaciones, el peruano arroja a Henríquez Ureña al campo del materialismo histórico. ${ }^{4}$ Sin embargo, en ambos casos — desde diferentes vías- se rinde tributo a una idea eurocéntrica según la cual un intelectual proveniente de un país "atrasado", de una región periférica es incapaz de articular una práctica literaria universal. ${ }^{5}$ Al mismo tiempo, esta visión contradice la propia genealogía intelectual de Henríquez Ureña que provenía, precisamente, de una isla perteneciente a la "América mala”, es decir, tropical y caribeña. ¿Cómo justificar, entonces, su propia formación y desarrollo intelectual durante sus primeros años en Santo Domingo y que marcan su vocación, o la de Rubén Darío, un hijo de Metapa que lleva una impronta

\footnotetext{
${ }^{4}$ Este pasaje de los Ensayos de Henríquez Ureña es verdaderamente interesante: "El arte y la literatura no florecen en sociedades larvadas o inorgánicas, oprimidas por los más elementales y angustiosos problemas de crecimiento y estabilización. No son categorías cerradas, autónomas, independientes de la evolución social y política de un pueblo”. Henríquez Ureña se coloca a este respecto en un terreno materialista e histórico" (2000:730).

${ }^{5}$ Cfr. María Teresa Gramuglio. "Tres problemas para el comparatismo”, en Orbis Tertius, 2006, XI (12).
} 


\section{Claudio Maíz}

inicial no muy diferente a la del dominicano? En un estudio sobre el universo familiar en su formación intelectual se señala que, en ocasiones, Henríquez Ureña era presentado como mexicano y no dominicano, en razón de que resultaba complicado "hacer creer que un erudito" de su categoría "hubiera podido nacer y crecer en Santo Domingo".

Las grandes ciudades de América no se encuentran en la base de la formación intelectual de Henríquez Ureña pero sí contribuyeron a incrementar y a enriquecer su cultura humanística antes que a su formación intelectual (Piña-Contreras, 2000:457).

\section{VARIACIONES DE UN ACORDE MAYOR}

A esta altura ya contamos con un dato relevante: los textos de Henríquez Ureña deben ser alejados de cualquier lectura autorreflexiva, en la que el lector busque reforzar sus propios supuestos sobre América Latina, tanto como rechazar la creencia de que son unívocos. Es así como dentro de la cohesión global de la obra de Henríquez Ureña es posible indicar algunas alteraciones sustantivas que permitirían convertirlas en etapas, en virtud de la trascendencia que revisten. Ellas serían: 1) etapa positivista, 2) humanismo clásico y 3) revisión crítica del legado occidental. El tránsito entre la primera y la segunda se produce hacia el año 1907, mientras que de esta última a la tercera, la Gran Guerra parece constituir el hito delimitador. Estas etapas, además de incidir, en general, en los problemas por él indagados, tienen especial importancia en lo que se refiere a la noción de mestizaje cultural en tanto teoría explicativa del desarrollo cultural de América Latina. El mestizaje vino a sustituir otros modos de desciframiento de la realidad americana, como es el caso de "civilización y barbarie". La determinación de los "principios" se sitúa dentro del debate por el esclarecimiento de una identidad. Establecer un origen es expresar, también, una definición con incidencias ulteriores. Entre las diferentes secuencias que pueden indicarse (y que van de un polo al otro de los componentes culturales hispanoamericanos, autóctonos y europeos), existe una que, como se ha dicho, nos interesa especialmente: el mestizaje como una teoría cultural.

Sin embargo, si bien es notorio este cambio por etapas hay aspectos centrales de su obra que permanecen inalterables. Se trata de la firme convicción en la función formativa del hombre que posee la cultura. Ideal, sin dudas, humanista - de cuño renacentista en gran medida - pero que pasaba por alto las bases sobre las cuales ese humanismo europeo/occidental se asentaba. La fe en las minorías ilustradas era factible soslayando parte del cuadro histórico de la situación mundial y latinoamericana. El mundialismo — si así puede llamarse al afán occidentalizante de Henríquez Ureña — se 
limitaba a la tradición europea y de ella, desde luego, a las expresiones más clásicas, especialmente griegas. La fascinación por lo bello, a veces, fue más poderosa que el interés por lo ético-político. En más de una oportunidad fue acusado de abandonar sus deberes políticos hacia su isla natal, como también para el resto de Hispanoamérica, al no pronunciarse contra algunos despotismos puntuales.

No es que a Henríquez Ureña le faltara información o preocupación, sino que carecía de entusiasmo por una función política del intelectual. ${ }^{6}$ Aquella "torsión ética" con la que su amigo Alfonso Reyes definía, en general, la literatura hispanoamericana no llegó a tocarlo en el sentido más explícito, a la manera de su admirado José Martí o, incluso, del mismo José Enrique Rodó, quien transitó la arena política uruguaya. Quizás, una de las pruebas más claras de lo que decimos aflore de la lectura del epistolario íntimo que Reyes y el dominicano construyeron a lo largo de más de cuarenta años. "Del mundo no hablemos. Silencio y sufrimiento", le escribe Reyes en carta personal a Henríquez Ureña nada menos que en 1940, apenas comenzado el conflicto bélico en Europa. Asimismo, la alusión a las cuestiones políticas americanas es extremadamente escasa cuando no inexistente. Es la misma sorpresa que se experimenta al leer las Memorias y el Diario de Henríquez Ureña (ambos abarcan un lapso entre 1909-1911) al advertir que no hay una mención a la Revolución Mexicana, episodio del que es testigo, pues se encuentra en el país azteca para entonces.

Si es verdad que Henríquez Ureña es un modelo del intelectual moderno, lo sería por el hecho de haber trabajado denodadamente por el esclarecimiento de un campo autónomo del trabajo intelectual, esto es, lejos de la praxis. Por lo menos política, no así de otra praxis, en que lo cultural adquiere ribetes desmesurados, en tanto labor, disciplina, esfuerzo puestos en la prosecución de objetivos editoriales, periodísticos, divulgadores, conferencistas, etc. Si la praxis política abrumó la vida productiva de letrados del siglo XIX, la praxis cultural será el ideal del intelectual que se perfila en la vida y obra del dominicano ¿Era ello posible o deseable? Es decir, ¿Existe un modo idóneo de establecer las delimitaciones entre una y otra praxis? Aquí se debe mencionar a José Enrique Rodó, para quien una ética fuerte será la respuesta a

\footnotetext{
${ }^{6}$ Por cuanto nos parece que se necesita especificar más el alcance de "la función pública del intelectual” que Díaz Quiñones le concede a Henríquez Ureña compartimos, parcialmente, su afirmación respecto a que la tercera línea de los beginnings del dominicano consiste en "la estrecha identificación entre cultura y orden que sostiene su obra. Henríquez Ureña concebía la modernidad como un conflicto del orden frente a la anarquía. Ese dilema exigía el cultivo de una autodisciplina basada en la ética del trabajo y una vocación para la función pública del intelectual. Su obra crítica es fruto de la extrema disciplina que privilegiaba estoicamente la inteligencia sobre el sentimiento” (2006:176).
} 


\section{Claudio Maíz}

una política caótica, anarquizante o inconducente, que muchos de estos hombres letrados vieron en la historia reciente y en la del siglo XIX. El ideal Belleza/Verdad platónico vertebra la obra de Rodó y la corriente occidentalista moderna hispanoamericana creada a través de Ariel, a cuya estirpe pertenece Henríquez Ureña.

Aun con lo verdadera que pueda ser la disyunción entre la praxis política y praxis cultural que aflora en Henríquez Ureña, su planteo no debe ocultarnos que en algún punto ambas prácticas emiten señales conjuntas. Esto lo decimos pensando en el plexo de rechazos que acompaña al arielismo en general como corriente cultural (Devés, 2000) y, en particular, en Henríquez Ureña. Entre los rechazos más notables se planteaba el temor a la constitución de una sociedad "mediocre" como fruto del avance democratizador. Frente a ello se alza como muralla protectora la idea del entroncamiento a la armonía que emana de la cultura grecorromana, en la que conviven la razón y el sentimiento, la acción y la belleza, a la manera de Federico Schiller en Educación estética del hombre (1794), al tiempo que ese proceso llevaría al encumbramiento de una guía intelectual formada por los mejores y más cultos. Estos guías o "maestros" debían representar la mejor tradición de la crítica occidental, en la que el inglés Matthew Arnold ocupaba un sitio preferencial, no menor, que el de E. Renan.

\section{ESTABILIDAD, ARMONÍA: ESTRATEGIAS DEL MESTIZAJE}

La reflexión crítica de Matthew Arnold (1822-1888) puede suministrarnos algunas pistas sobre la manera como aquellas praxis políticas y culturales se avienen a reunirse en algún punto. De los probables, nos interesan aquellos puntos en los que, a nuestro juicio, se intersectan el humanismo y el mestizaje. Ya veremos algunas razones más, pero adelantemos que el mestizaje, como confluencia de dos elementos diferenciados pero que se armonizan, sugiere la idea clásica del justo medio. El mestizaje es visto, entonces, como una concomitancia en la que las partes se equilibran en proporciones iguales. El humanismo, en ese sentido, pudo haber aportado los argumentos convenientes o, mejor todavía, la teoría del mestizaje no habría que verla sino al trasluz del humanismo. Pero no cualquier humanismo, para lo cual es preciso volver a Arnold, quien planteó con claridad que el crítico debe distanciarse de las cosas prácticas, no debe prestarse a consideraciones políticas o prácticas, es decir, que la crítica verdadera debe ser independiente de intereses sectoriales. Por otra parte, Arnold fue uno de los primeros que reaccionaron frente a la secularización de 
la vida cotidiana y ve en la poesía el sustituto ideal de la religión. ${ }^{7}$ El perfeccionamiento humano podía prescindir de la religión mediante "la sustitución de una moralidad cristiana por normas éticas humanistas" (Franco, 2000:812). Ésta sería la apreciación admitida, en el revés de trama del ciclo que va de fines del siglo XIX a las primeras décadas del XX, sin embargo, es factible rearmar el significado de ese juicio. Según Jean Franco, el humanismo es la solución ideológica a la lucha de clases en los pensadores europeos (Arnold, Renan). ${ }^{8}$ Para nosotros, en cambio, no tendría ese sentido fuerte entre los intelectuales arielistas. El arielismo fue la más acabada síntesis de aquel humanismo, por tanto, Ariel puede verse como un "manual del humanismo” en América Latina (Franco, 2000:815). En resumidas cuentas, el humanismo arielista resulta, también, una solución ideológica a un problema concreto aunque, en este caso, sería el de la desintegración social que padece América Latina, en la que el mestizaje viene a ser una de las aristas.

"El problema de la América española —escribe Henríquez Ureña en La utopía de América - es todavía su integración social” (1978:18). El mestizaje, al interpretarse como el equilibrio, resultaba la mejor doctrina para producir — al menos desde el plano ideológico — un intento de integración de la diversidad, una reducción a la unidad de lo múltiple y conflictivo. Escribe Henríquez Ureña sobre el problema del indio

En nuestros días el problema político se ha planteado de nuevo con urgencia. En el momento de la Independencia, habíamos abolido la esclavitud de la raza negra, aunque subsistía siempre el problema del indio. El Indio no era esclavo, pero tampoco era verdaderamente libre. La abolición de la encomienda colonial, que lo había convertido en siervo bajo el pretexto de protegerlo y educarlo, no lo había liberado

\footnotetext{
${ }^{7}$ Cfr. Vernon Hall. Jr. Breve historia de la crítica literaria. México: F. C. E., 1982; Terry Eagleton. "Ascenso de las letras inglesas”, en Una introducción a la teoría literaria. México: F. C. E., 1988; Mattew Arnold. Culture and Anarchy. London: The Cambrige University Press, 1960.

${ }^{8}$ Eagleton subraya con intensidad —e ironía — esta dimensión ideológica de la literatura en un capítulo que dedica al ascenso de las letras inglesas, en el que trata a Arnold. "En diversas formas la literatura era un candidato apropiado para esta empresa ideológica. Como labor "humanizadora" podría suministrar un eficaz antídoto contra el fanatismo político y el extremismo ideológico. Puesto que la literatura, como sabemos, se ocupa más bien de valores humanos universales y no de trivialidades históricas como las guerras civiles, la opresión de las mujeres o los despojos que sufre el campesino inglés, podría servir para colocar en perspectiva las mezquinas exigencias de los trabajadores en lo relativo a un nivel de vida decente o a un mayor control de su propia vida, e incluso, con algo de suerte, hasta podría hacérseles olvidar esas cosas y sumergirlos en la profunda contemplación de verdades y bellezas eternas” (1988:38).
} 


\section{Claudio Maíz}

realmente. Se había convertido en una especie muy rara de proletario. No fue sino en el siglo XX cuando se supo encarar el problema del Indígena. Se vio entonces que las fórmulas socialistas europeas poco tenían que ver con el problema del Indígena americano. El Indígena no es el proletario del industrialismo. El Indígena vive sobre todo en los países que no se han industrializado o que sólo lo han sido en una medida muy limitada, como México, de manera que las soluciones adoptadas a su respecto no podían ser francamente socialistas (1978:18).

Aunque descarta una solución socialista al problema de indio —quizás en una implícita respuesta a la obra de Juan Carlos Mariátegui- no declara con precisión cuál podría ser entonces el camino, pese a reconocer las muy "avanzadas disposiciones para la regeneración del Indígena” o el "empeño en la búsqueda de soluciones satisfactorias” (1978:19). Sospechamos que no había respuesta formada para proponer. Al fin de cuentas, el enfoque de estos temas, englobados muchas veces en la llamada "cuestión social”, oscilaba entre la encíclica papal o el maximalismo anarquista. En este marco, la tradición humanista y en especial la cultura clásica subsanan "el vacío ideológico en naciones dirigidas por oligarquías cuya única forma de mantenerse en el poder era la represión” (Franco, 2000:815). Para Henríquez Ureña, la función de las humanidades —que pasaba por el estudio de la cultura griega - no era solamente "enseñanza intelectual y placer estético, sino también, como pensó Mattew Arnold, fuente de disciplina moral. Acercar a los espíritus a la cultura humanística es empresa que augura salud y paz” (2000:24). En otras palabras, la cultura clásica entendida como un recurso de contención al desborde moral y social pero, también, con consecuencias disciplinantes.

La "sofrosine" —quizás el sustituto de la conflictividad en la estructura del discurso cultural de entonces- es la virtud más ensalzada por el humanismo arielista, razón suficiente para que el imperativo del intelectual consista en templarse a través de la disciplina, el trabajo, el rigor y, así, hacerse merecedor de ella. ${ }^{9}$ Quien posea esa virtud podrá integrar el plantel de los “conductores" de la sociedad. Al imponerse la razón se habrá impuesto, simultáneamente, una manera más legítima de guiar la polis. Todo es cuestión de esperar el desarrollo de un proceso que, una vez cumplido, al decir de Renan "Nuestra época de pasión o de error aparecerá entonces como la pura

\footnotetext{
${ }^{9}$ Sobre los vínculos entre orden y cultura en Henríquez Ureña, escribe Díaz Quiñones: “Ese dilema exigía el cultivo de una autodisciplina basada en la ética del trabajo y una vocación para la función pública del intelectual. Su obra crítica es fruto de la extrema disciplina que privilegiaba estoicamente la inteligencia sobre el sentimiento” (2006:176).
} 
barbarie, o como la edad caprichosa y antojadiza que en el niño separa los encantos de la infancia, de la razón del hombre” (1943:32).

No es todo fusión, desde luego, en la América española. Ni la fusión es siempre completa: quedan gruesos núcleos indios a quienes no ha alcanzado, o apenas, la cultura europea, y viven de supervivencias. No son casos graves, como antes creíamos, esas supervivencias. Las que describe Robert Redfield en su libro sobre Tepoztlán ${ }^{10}$ salvan de la fábrica o de la mina, o de la plantación, al nativo, mientras llega la ocasión de incorporarlo eficazmente, sin desmedro suyo, a la cultura de tipo europeo. Grave caso, sí, el del indígena, o el del mestizo, que de la cultura europea no ha adquirido sino el idioma y, si acaso, la exigua vestimenta, pero que ha caído en la situación de proletario, desconocida para la economía anterior a la conquista, tanto en las tribus de vida rudimentaria como en los “imperios" cuya minuciosa organización evitaba la indigencia.

"El problema de la América española es todavía su integración social”, sostiene Henríquez Ureña (2000:29), afirmación que puede leerse a la luz de la objeción hecha al mestizaje, es decir, en tanto "proceso de blanquecimiento biológico, económico y cultural” — en su caso, de la sociedad caribeña- - que debe cumplir una serie de pasos sucesivos hacia el "progreso", que no es sino alcanzar la cultura europea. Es necesario decirlo, el mestizaje o la "fusión" - para el dominicano - se traduce en adquisición de la cultura europea por parte de los núcleos indígenas. Aun admitiendo la alternativa de que ese proceso no se complete, ello por sí solo no representa un caso grave. Sin embargo, lo deseable es que la incorporación a la cultura europea se realice “eficazmente”. Grave resulta, sin embargo, el caso del indígena proletarizado cuando no puede eludir la indigencia, provocada por la sociedad capitalista a la que no se integra. Ese es el precio que paga por haberse "eficazmente" incorporado a la tradición europea del trabajo y de la tecnología. Como se observa, la fusión no consiste en una operación de mezcla sino, más bien, en la acción de fundir el elemento indígena en el crisol europeo dominante. Al fin de cuentas, no se trata de una asimilación sino de una adquisición pendiente. De ahí que, en opinión del dominicano, en "lo importante y ostensible se impuso el modelo de Europa; en lo doméstico y cotidiano se conservaron muchas tradiciones autóctonas” (1978:28).

La cultura colonial, descubrimos ahora, no fue mero trasplante de Europa, como ingenuamente se suponía sino, en gran parte, obra de fusión,

\footnotetext{
${ }^{10}$ Robert Redfield (1897-1958), antropólogo y autor de Tepoztlan, a Mexican Village. A study in Folk life. Chicago: University of Chicago Press (1930). El Calpulli barrio en un pueblo mexicano actual (1928); The Folk Culture of Yucatán (1941); A Village that Chose Progress (1950); The Primitive World and Its transformations (1953), entre otras obras.
} 


\section{Claudio Maíz}

fusión de cosas europeas y cosas indígenas. De eso se ha hablado, y no poco, a propósito de la arquitectura: de cómo la mano y el espíritu del obrero indio modificaban los ornamentos y hasta la composición: "la fusión no abarca sólo las artes: es ubicua” (1978:28).

¿Cómo llega a gestarse la vía del mestizaje como aplicación del "justo medio"? En el pasaje de un momento a otro - recordemos que hemos señalado tres momentos diferenciados en la obra del dominicano- comienza a producirse, de acuerdo con nuestra hipótesis, el cambio que implica el abandono de la antimetafísica, la fe en la ciencia y la confianza en el progreso indefinido. Esta misma mutación es posible pesquisarla, en el contexto de la época, por medio de la renuncia a los postulados generales del positivismo y la adhesión a la corriente idealista. Con matices y autores diversos, el sentido general de la mutación se percibe en las postrimerías del siglo XIX y comienzos del XX, tanto en promociones intelectuales españolas: el caso emblemático del cambio lo constituye la crisis de Miguel de Unamuno (hacia 1897) como en el novecentismo hispanoamericano. Ya se ha dicho, el año 1907 puede indicarse como punto de partida de Henríquez Ureña en la adscripción al helenismo. Como él mismo lo confiesa, en ese año sus gustos intelectuales cambian. Dos lecturas señala Henríquez Ureña como las responsables del giro: Platón y Walter Pater (1839-1894), es decir, el filósofo y su intérprete (1989:149).

El giro tuvo verdaderos visos de conversión en un propicio ambiente compartido con Gómez Robledo, Acevedo y Reyes que ya leían a los griegos. A tal punto llegó la veneración a Pater, el autor de Estudios griegos (1895), que el dominicano lo puso de "moda” entre los jóvenes mexicanos y tradujo al español dicho libro un año después del comienzo de la conversión al helenismo. La lista de sus lecturas es extensa. Un somero repaso nos permite avizorar el aparato conceptual que va formando: Goethe, Friedrich Schiller, Hegel, Schopenhauer, Heinrich Heine, Mattew Arnold, Ernest Renan, Adolphe Taine, Alfred Fouillée; también la Historia de la filosofía de Alfred Weber, la Historia de Grecia de Ernest Curtius (1989:140). El giro helenístico de Henríquez no consiste sencillamente en la sustitución de una filosofía por otra, sino que encierra, por una parte, una dimensión crítica del positivismo que se abandona, por otra, el recorrido de una senda autoformativa en la que el platonismo lo "conquista, literaria y moralmente". En sus Memorias, escribe que

En el orden filosófico he ido modificando mis ideas, a partir, también, del mismo año 1907. Mi positivismo y mi optimismo se basaban en una lectura casi exclusiva de Spencer, Mill y Haeckel; las páginas que había leído de filósofos clásicos y de Schopenhauer y Nietzsche no me habían 
arrastrado hacia otras direcciones. Sobre todo, no trataba yo sino con gentes más o menos positivistas o, de lo contrario, creyentes timoratos y de antifilosóficos. El positivismo me inculcó la errónea noción de no hacer metafísica /.../ y a nadie conocía yo que hiciera otra metafísica que la positivista, la cual daba ínfulas de no serlo /.../ (1989:141).

Retoma el tema del cambio en "La cultura de las humanidades", un ensayo de 1914, en el que insiste sobre el año 1907 como clave del abandono del positivismo y a la reaparición de las inquietudes metafísicas, circunstancia reforzada en 1910 con la oración a Barreda de Justo Sierra (2000:21). Bien podría pensarse que en el lema "orden y progreso", verdadera divisa del positivismo, la gran alteración vendría dada por la renuncia al carácter indefinido del progreso, pero en lo que concierne al orden, poco y nada habría variado a no ser que se lo remontase a otros principios filosóficos. El Ateneo de la Juventud donde se fermenta esta dinámica cultural llegó a contar con más de sesenta miembros, destacando el grupo de los cuatro grandes: José Vasconcelos, Antonio Caso, Pedro Henríquez Ureña y Alfonso Reyes. Un grupo más amplio fue el de Martín Luis Guzmán, Julio Torri, Ricardo Gómez Robledo, Jesús T. Acevedo, Enrique González Martínez, Manuel M. Ponce y Diego Rivera. De este núcleo helenístico del Ateneo habrá de surgir con el tiempo una metáfora sobre la situación de la cultura hispanoamericana en el contexto mundial. Nos referimos al tópico recurrente del banquete en Alfonso Reyes (aquel que utiliza en su ensayo sobre la inteligencia americana: "Llegada tarde al banquete de la civilización europea”). En efecto, el tópico se torna recurrente en una serie de ensayistas mexicanos, ${ }^{11}$ cuya circulación comienza dentro de aquel círculo de jóvenes mexicanos, que integra el mismo Henríquez Ureña, quien recuerda que "Una vez nos citamos para releer en común el Banquete de Platón” (2000:21). ${ }^{12}$

La renuncia al progreso por descrédito de una condición indefinida, universal y fatalista que se le atribuía dejaba sin orientación general a la sociedad hispanoamericana. Nada más ajeno al espíritu utópico de Henríquez Ureña. El lugar del progreso debía ser ocupado por el propósito de la estabilidad, la búsqueda más excelsa que le asigna a las grandes civilizaciones. "Todas estas civilizaciones tuvieron como propósito final la estabilidad, no el progreso; la inquietud perpetua de la organización social, no

\footnotetext{
${ }^{11}$ Cfr. Diana Castilleja Madaleno. "Entramados intertextuales en el ensayo mexicano”, en Cuadernos Americanos, Nº 99 (2003): 120-157.

${ }^{12}$ Desde luego que la línea de indagación es tentadora y podría continuarse estableciendo el enlace de Platón y el helenismo hasta la contracara del "banquete" que es la devoración, propia de la antropofagia de la vanguardia brasileña. Ambos tópicos actúan como manera de comprender la relación de Europa con América.
} 


\section{Claudio Maíz}

la perpetua inquietud de la innovación y la reforma” (2000:23). Si entre los griegos hay progreso, es porque existe el impulso del mejoramiento individual y la búsqueda de la perfección.

En "La tradición en los pueblos hispanoamericanos", ensayo de 1915, Rodó advertía sobre el extremo valor que se le había conferido a la concepción del progreso indefinido, a tal extremo de alcanzar el nivel de una verdadera "fe sustitutiva de las creencias religiosas en el espíritu de las muchedumbres” tanto como de sus dirigentes (1967:1203). Como se sabe, el positivismo constituyó una verdadera ideología estatal que imprimió la fuerza necesaria para encarar la organización del estado y la modernización de la vida pública e institucional. Sin embargo, aun con todo lo benéfico (según desde donde se lo mire) que la doctrina del "progreso indefinido" pudo tener, su aplicación se hace sobre la negación de la tradición o sobre "el injusto menosprecio" de ella, lo cual implica invariablemente "el desconocimiento vano y funesto de la continuidad solidaria de las generaciones humanas" (1967:1203) y, lo que es peor, el enfrentamiento entre el pasado y el presente. Este antagonismo produce un supremo rechazo en un espíritu como el de Rodó. A la batalla entre pasado y presente, Rodó prefiere "la relación de padre a hijo o de dos obreros de sucesivos turnos, dentro de una misma interrumpida labor" (1967:1203). He aquí la punta de la madeja que teje la trama cultural sin dependencia alguna del conflicto y que llega hasta Henríquez Ureña y aún más allá.

El gran dilema que se le plantea a Rodó como a la generación que lo antecede y precede, tiene que ver con la determinación de los "principios", esto es - y para decirlo en otros términos - “desde cuándo y hasta dónde” se

constituye la tradición, según Rodo, "si hemos de mantener nuestra personalidad colectiva, necesitamos reconocernos en el pasado y divisarlo constantemente por encima de nuestro suelto velamen” (1967:1205). La tradición en América carece de "valor dinámico" argumenta, pero no solamente por el "escaso arraigo en el tiempo" que la caracteriza, sino principalmente por una "tradición de ruptura" que se expresa desde las luchas por la independencia, a la manera de "un divorcio y oposición casi absolutos entre el espíritu de su pasado y las normas de su porvenir" (1967:1204). Una de las primeras observaciones importantes hecha sobre la obra de Rubén Darío pertenece a Rodó, advirtiendo que no era, o no podía ser, el poeta de América, entre otras causas, porque no hundía su obra poética en los campos de una tradición

Ignoro si algún espíritu zahorí podría descubrir, en tal cual composición de Rubén Darío, una nota fugaz, un instantáneo reflejo, un sordo rumor, por las que se reconociera en el poeta al americano de las cálidas 
latitudes, y aun al sucesor de los misteriosos artistas de Utatlán y Palenke; como, en sentir de Taine, se reconoce — comprobándose la persistencia del antiguo fondo una raza — al nieto de Néstor y de Ulises en los teólogos disputadores del Bajo Imperio (1967:169).

Podemos concluir diciendo que Pedro Henríquez Ureña encaja sin dificultad alguna en los moldes del intelectual moderno, por su mirada unitaria y entusiasmo totalizador. Elaboró una imagen de Hispanoamérica a partir de estratégicos recortes y omisiones que abonaron su tendencia a la unidad. Desde el plano historiográfico sostuvo una estructura alentada por el optimismo — como un resto del positivismo que lo ganó hasta 1907- y soslayó el conflicto como categoría del cambio. La adhesión a la tradición, al orden y a la continuidad apela a coordenadas histórico-culturales que provienen de su terminante afirmación de la pertenencia de Hispanoamérica a la antigua Romania, en una intensa reivindicación de esa estirpe occidental. El mestizaje, en ese cuadro ideológico, puede leerse al trasluz del humanismo al que se adscribe. La "sofrosine" y el "justo medio" son algunos de los principios del humanismo practicado que auxilian su idea de la fusión de culturas. Aunque, como se observó, la operación no consiste en una fusión proporcional sino en un camino a recorrer, un trayecto que debe cumplimentarse y en cuya estación final se ubica la herencia cultural europea.

Universidad Nacional de Cuyo* Facultad de Filosofía y Letras Consejo Nacional de Investigaciones Científicas y Técnicas Ciudad Universitaria, Parque General San Martín 5500 Mendoza (Argentina) cmaiz@uncu.edu.ar

\section{BIBLIOGRAFÍA}

ARNOLD, Mattew. Culture and Anarchy. London: The Cambridge University Press, 1960.

BENÍTEZ ROJO, Antonio. La isla que se repite. El caribe y la perspectiva posmoderna. Hannover: Ediciones del Norte, 1989.

CASTILLEJA MADALENO, Diana. "Entramados intertextuales en el ensayo mexicano”, en Cuadernos Americanos, № 99, 2003.

DEVÉS, Eduardo. "El entorno arielista", en Del Ariel de Rodó a la CEPAL (1900-1950). Buenos Aires: Biblos, 2000.

DÍAZ QUIÑONES, Arcadio. Sobre los principios. Los intelectuales caribeños y la tradición. Universidad Nacional de Quilmes, 2006. 


\section{Claudio Maíz}

EAGLETON, Terry. "Ascenso de las letras inglesas”, en Una introducción a la teoría literaria. México: Fondo de Cultura Económica, 1988.

FRANCO, Jean. "El humanismo de Pedro Henríquez Ureña”, en Henríquez Ureña, Pedro. Ensayos. Edición crítica José Luis Abellán, Ana María Barrenechea (coordinadores). Madrid-París-Barcelona-México-Buenos Aires-Sao Paulo-Lima-Guatemala-San José-Santiago de Chile: ALLCA XX, 2000, (Colección Archivos $\mathrm{N}^{\circ} 35$ ).

GRAMUGLIO, María Teresa. "Tres problemas para el comparatismo", en Orbis Tertius, 2006, XI (12).

HALL, Vernon Jr. Breve historia de la crítica literaria. México: Fondo de Cultura Económica, 1982.

HENRÍQUEZ UREÑA, Pedro. Memorias. Diario. Introducción y notas por Enrique Zuleta Álvarez. Buenos Aires: Academia Argentina de Letras, 1989.

OSORIO, Jaime. "El estudio de América Latina frente al positivismo y al posmodernismo", en Cuadernos Americanos, Nº 118 (2006).

PIÑA-CONTRERAS, Guillermo. "El universo familiar en la formación intelectual de Pedro Henríquez Ureña”, en Henríquez Ureña, Pedro. Ensayos. Edición crítica José Luis Abellán, Ana María Barrenechea (Coordinadores). Madrid; París; Barcelona; México; Buenos Aires, Sao Paulo; Lima; Guatemala; San José; Santiago de Chile: ALLCA XX, 2000, (Colección Archivos $\mathrm{N}^{\circ}$ 35).

QUINTANILLA OSORIO, Susana. "La formación de los intelectuales del Ateneo”, en Historias, N²6, abril 1991-septiembre 1991.

RENAN, Ernesto. El porvenir de la ciencia. Buenos Aires: Americalee, 1943.

------- La utopía de América. Prólogo de Rafael Gutiérrez Girardot. Compilación y Cronología Ángel Rama y Rabel Gutiérrez Girardot. Caracas: Ayacucho, 1978.

------- Ensayos. Edición crítica José Luis Abellán, Ana María Barrenechea (Coordinadores). Madrid-París-Barcelona-México-Buenos Aires-Sao Paolo-Lima-Guatemala-San José-Santiago de Chile: ALLCA XX, 2000, (Colección Archivos $\mathrm{N}^{\circ} 35$ ).

------- "Los libros del Ateneo", en Historias, No 29 (octubre 1992marzo1993).

RODÓ, José Enrique. Obras Completas. Introducción, prólogo y notas por Emir Rodríguez Monegal. Madrid: Aguilar, 1967.

SARLO, Beatriz. "Pedro Henríquez Ureña: lectura de una problemática”, en Henríquez Ureña, Pedro. Ensayos. Edición crítica José Luis Abellán, Ana María Barrenechea (Coordinadores). Madrid-París-BarcelonaMéxico-Buenos Aires-Sao Paulo-Lima-Guatemala-San José-Santiago de Chile: ALLCA XX, 2000 (Colección Archivos Nº 35). 